\title{
Allium sativum L.: the anti-immature leech (Limnatis nilotica) activity compared to Niclosomide
}

\author{
Mahmoud Bahmani • Javad Abbasi • \\ Ava Mohsenzadegan • Sirous Sadeghian • \\ Majid Gholami Ahangaran
}

Received: 18 September 2011 / Accepted: 29 November 2011 /Published online: 15 December 2011

(C) The Author(s) 2012. This article is published with open access at Springerlink.com

\begin{abstract}
This study was carried out to determine the effects of methanolic extracts of Allium sativum L. on Limnatis nilotica compared with Niclosomide. In this experimental study in September 2010, a number of leeches (70 in total) from the southern area of Ilam province were prepared, and the effects of methanolic extract of A. sativum L. with Niclosomide as the control drug were compared and distilled water was evaluated as the placebo group which investigated L. nilotica using anti-leech assay. The average time of paralysis and death of L. nilotica for Niclosomide $(1,250 \mathrm{mg} / \mathrm{kg})$ and the methanol extract of $A$. sativum L. $(600 \mu \mathrm{g} / \mathrm{ml})$ were $6.22 \pm 2.94$ and $68.44 \pm 28.39 \mathrm{~min}$, respectively. Distilled water and garlic tablets at a dose of $400 \mathrm{mg}$ were determined as the inert group. In this research, the attraction time of the leeches' death among different treatments is significant. In this study, it was determined that Niclosomide, with an intensity of $4+$, and methanolic extracts of A. sativum L., with an intensity of $3+$, have a good antileech effect and can be shown to be effective in cases of leech biting, while distilled water was negative.
\end{abstract}

M. Bahmani $\cdot$ M. G. Ahangaran

Young Researchers Club,

Shahrekord Branch,

Islamic Azad University, Iran

\section{J. Abbasi $(\bowtie) \cdot$ A. Mohsenzadegan}

General Veterinary Student, Faculty of Veterinary Medicine,

Tehran University,

Tehran, Iran

e-mail: jabbasi@ut.ac.ir

\section{S. Sadeghian}

Department of Animal Science,

Faculty of Veterinary Medicine, Tehran University,

Tehran, Iran
Keywords Limnatis nilotica $\cdot$ Allium sativum L. . Niclosomide $\cdot$ Paralysis and death

\section{Introduction}

Leeches, hermaphroditic, blood-sucking parasites, are rarely reported in humans and animals as a cause of many problems. They vary in color, length, and shape (Ahmadizadeh 2002). Leeches that cause parasitic pollution in humans are terricolous or aquatic. Terricolous or land leeches include Haemadipsa zylanica, Haemadipsa sylvestris, and Haemadipsa picta, while aquatic leeches include Limnatis nilotica, Myxobdella africana, Dinobdella ferox, Phytobdella catenifera, and Teromyzon tessulatom (Haycox et al. 1995; Vera et al. 2005; Wallis 1988). Leeches mainly inhabit in ponds, lakes, and streams. When water containing young leeches is drunk without necessary caution, leeches enter through the mouth and attach to the upper respiratory system or the digestive system mucosa (Pandey et al. 2000). These locations are mostly the nose, nasopharynx, oropharynx, tonsils, esophagus, and occasionally larynx mucosa. Serious complications can include dyspnea, hemoptysis (Pandey et al. 2000) or hematemesis, and vaginal bleeding. Garlic, an indigenous dietary component, belongs to the Liliaceae family and is widely used as a condiment; besides, it is also used in pharmacotherapy against debilitating pathologies because of its antioxidant, anti-hyperglycemic, antimicrobial, antifungal, antithrombotic, antineoplastic, and antiinflammatory activities (Mayeux et al. 1988; McGrindle et al. 1998; Isaacsohn et al. 1998; Koscienly et al. 1999; You et al. 1989; Sabayan et al. 2007; Ledezma and Apitz-Castro 2006; Chung 2006; Sumioka et al. 2006; Su et al. 2006; Zargari 1996). It is an effective drug with no side effects and, as it offers an appropriate cost benefit, the decision 
Table 1 Scientific name and family name, local name, part used, province, extract type, and traditional treatment

\begin{tabular}{llllll}
\hline Scientific name and family name & Local name & Part used & Province & Extract type & $\begin{array}{l}\text { Traditional treatment } \\
\text { (Ghasemi-pirbalouti 2008) }\end{array}$ \\
\hline Allium sativum L. (Liliaceae) & Garlic & Bulbs & Tehran & Methanolic extract & Antiparasite \\
\hline
\end{tabular}

was made to study the anti-leech effects of some herbal and chemical compounds. Considering the effective antiparasitic property of garlic (Allium sativum L.), an attempt has been made in the present study to evaluate the efficacy action of the methanolic garlic extract against immature form of leech (L. nilotica) in comparision with Niclosomide.

\section{Materials and methods}

\section{Study design}

In this study, a number of L. nilotica immature leeches (70 in total), 30-100 $\mathrm{mm}$ in length, were selected from spring water in the southern region of Ilam province (Western Iran). They were dark green in color with rows of green spots on the dorsal surface, yellowish orange and dark green bands on either side, and, as mentioned, a 30-100-mm length - the main signs for the detection of L. nilotica immature species. Fresh garlic bulbs (A. sativum L./Liliaceae), a popular spice, were preferred.

Methanolic garlic extract preparation

The methanolic garlic extract was prepared by adding 1:3 ratios of garlic and methanol, respectively, and this was subjected to Soxhlet extraction for $72 \mathrm{~h}$ according to the prescribed method of Eidi et al. (2006). After extraction, the solvent was filtered. The information gathered from the study of the garlic plant has been determined in Table 1. Garlic pills (Garlet) were provided by the Amin Pharmacy Company of Iran. Niclosomide tablets $(1,250 \mathrm{mg} / \mathrm{kg}$ ) (an antiparasite) were investigated as a control and compared with distilled water. These tablets were powdered and diluted in $10 \mathrm{ml}$ distilled water.

\section{Anti-leech assay}

For the anti-leech assay, the leeches were located individually in a glass container with $600 \mathrm{ml}$ spring water. The extract and drug were then added and their effects observed for $720 \mathrm{~min}$, and time to paralyze, kill, and death of each leech was recorded. The evaluation of a leech's death was based on immobility after stimulation with a needle. The low average paralyzing and killing time of these compounds reflects anti-leech properties (Bahmani et al. 2010a, b).

The severity effect of these compounds/drugs based on time was categorized into five groups:

1. 4+: Paralysis and death of each leech within 1-60 min after addition of the drug,

2. 3+: Paralysis and death of each leech within 61120 min after addition of the drug,

3. 2+: Paralysis and death of each leech within 121180 min after addition of the drug,

4. 1+: Paralysis and death of each leech within 181240 min after addition of the drug, and

5. Negative: Paralysis and death of each leech within 241720 min after addition of the drug (Bahmani et al. 2010a, b).

The efficacy of the drugs which were able to kill leeches within 1-60 min after addition reflects the anti-leech properties of these compounds, and therefore, they may be used in the treatment of infestation with L. nilotica in the future (Bahmani et al. 2010a, b).

\section{Statistical analysis}

The differences between the control and the treated groups were analyzed using one-way ANOVA and Sigma State 2 program.

\section{Results}

The anti-leech activities for treatments on L. nilotica are shown in Table 2. The A. sativum L. extract showed anti-leech activities with a mean of $68.44 \mathrm{~min}(3+)$ in the paralysis and death of the leech (L. nilotica). An average time for Niclosomide

Table 2 Distribution of mean \pm SD for the anti-leech activity of methanolic extracts of Allium sativum L. and Niclosomide on the immature form of Limnatis nilotica

\begin{tabular}{llll}
\hline $\begin{array}{l}\text { Components } \\
\text { Drugs }\end{array}$ & Dose & Time (minute) & Severity \\
\hline Niclosomide & $1,250(\mathrm{mg} / \mathrm{kg})$ & $6.22 \pm 2.94$ & $4+$ \\
Methanolic garlic extract & $600(\mu \mathrm{g} / \mathrm{ml})$ & $68.44 \pm 28.39$ & $3+$ \\
Physiological water & $100(\mathrm{ml})$ & $720 \pm 0$ & - \\
Garlet & $400(\mathrm{mg} / \mathrm{kg})$ & $720 \pm 0$ & - \\
\hline
\end{tabular}


death was found to be $6.22\left(4^{+}\right)$. The result revealed that Garlet and distilled water are not effective in the death of L. nilotica. Among the treatments tested, Niclosomide and garlic methanol extract showed the best anti-leech activity. The highest effectivity was found for Niclosomide. Garlet and distilled water demonstrated no anti-leech effect (Table 2).

\section{Discussion}

Garlic (A. sativum L.) is a popular spice, a remedy for a variety of ailments, and is known for its medicinal uses as an antibiotic, antithrombotic, antineoplastic agent, and antiinflammatory activities (Ledezma and Apitz-Castro 2006; Chung 2006; Sumioka et al. 2006; Su et al. 2006; Sabayan et al. 2007). Leech infestation can lead to some side effects including anemia, bleeding, subsequent biting infections, ache, itching, inflammation, high sensitivity, and anaphylactic reactions (Ahmadizadeh 2002; El-Awad and Patil 1990; Hadrani et al. 2000; Mirzaei 2005; Raj et al. 2000; Estamble et al. 1992; Madill and Hovingh 2007; Schenkova et al. 2005). In some reports of human, leeches as a foreign body caused acute bleeding of the alimentary system (Kazemi and Bajoghli 2002), hematemesis (Hemmati et al. 2002), or bleeding of the vagina (Yaghmaee 2000), and one case of ophthalmorrhagia caused by leech attachment was reported by Davari (2008). This parasite in the respiratory tract has been reported in animals, and leeches infesting the nasal cavity were reported in one camel in Iraq. Some reports have mentioned that hirudiniasis may cause severe anemia with $\mathrm{Hb}<5 \mathrm{~g} / \mathrm{dl}$ (Hemmati et al. 2002).

Garlic, as an effective drug containing no side effects has been suggested for leeches. Hence, the decision was made to study the anti-leech effects of some herbal and chemical compounds. The results of this study showed that garlic methanolic extract $(600 \mu \mathrm{g} / \mathrm{ml})$ could kill leeches in an average time of $68.44 \pm 28.39 \mathrm{~min}$. The average death time for Niclosomide was found to be $6.22 \pm 2.94$. Garlet and physiological water showed no anti-leech effect. Trade names of garlic components in Iran include Garlet and Garcine pills, Garlic drop, Alicum powder, and the Alium$\mathrm{S}$ pill, which are commonly used to decrease blood cholesterol and triglycerides, cause excretion of esterified acids and alkalis, and decrease blood pressure and anticoagulation (Ghasemi-pirbalouti 2008). Garlic alkaloids have an antimicrobial and antihelminthic nature (Ghasemi-pirbalouti 2008). In the present study, the Garlet pill (without thiosulfinate) and fresh garlic extract were compared. The results revealed that garlic methanolic extract could kill the leech in an average of $68.44 \mathrm{~min}$, but Garlet had no anti-leech effect; therefore, thiosulfinate is a major component for killing leeches. Hashmi Fard (1996) reported that a combination of niclosamide and garlic pill could accelerate the remission of Taenia saginata and Hymenolepis nana. Soffar and Mokhtar (1991) evaluated the antiparasitic effects of aqueous garlic extract (diluted 1:20) in hymenolepiasis and giardiasis. Bahmani et al. $(2010 \mathrm{a}, \mathrm{b})$ studied the anti-leech effects of tobacco methanolic extract and also some other antiparasitic drugs such as mebendazole, metronidazole, triclabendazole, levamisole, and succinylcholine. The results of this study showed that tobacco methanolic extract $(600 \mu \mathrm{g} / \mathrm{ml})$ was able to kill the leaches in an average time of $17 \mathrm{~min}$. The average death times for other drugs (triclabendazole, levamisole, niclosamide, and metronidazole) were found to be $118.66,7,18.66$, and $541.11 \mathrm{~min}$, respectively. In the present study, like previous studies, Niclosomoide tablets $(1,250 \mathrm{mg} / \mathrm{kg})$ revealed anti-leech effects. Bahmani et al. (2010a, b) studied the anti-L. nilotica effects of seven anti-parasite drugs, from which closantel, ivermectin, and levamisole were determined at $4+$ severity, while triclabendasole $(3+)$, albendasole $(2+)$, mebendasole, and distilled water were of negative severity. Lun et al. 1994 revealed antiparasitic effects of diallyl trisulphaide (dasuansu) on human and animal pathogenic protozoa such as Trypanosoma sp., Entamoeba histolytica, and Giardia lamblia.

\section{Conclusion}

The present study revealed that garlic methanol extract had an anti-leech effect, and therefore, may be used in the treatment of infestation with L. nilotica in future.

Open Access This article is distributed under the terms of the Creative Commons Attribution Noncommercial License which permits any noncommercial use, distribution, and reproduction in any medium, provided the original author(s) and source are credited.

\section{References}

Ahmadizadeh A (2002) Leech infestation as a potential cause of hemoptysis in childhood. Arch Otolaryngol Head Neck Surg 128(1):92

Bahmani M, Avijgan M, Hosseini SR, Gholami Ahangaran M, Sadighara P (2010a) Comparison of anti-Limnatis nilotica effect of several anti-nematode, anti-trematodes and anti-cestodes drugs. Vet Res Bull 6(Sup. 1):51-54

Bahmani M, Avijgan M, Hosseini SR, Qorbani M (2010b) Evaluating the anti-Limnatis nilotica effects of tobacco methanol extract compared with succinyl choline and some other anti-parasite drugs. Shahrekord J Med Sci 12(3):53-59

Chung LY (2006) The antioxidant properties of garlic compounds: allyl cysteine, alliin, allicin, and allyl disulfide. J Med Food 9:205-213

Davari MA (2008) A case report of ophthalmorrhagia caused by leech attachment. Birjand J Med Sci 14(3):71-75 
Eidi A, Eidi M, Esmaeili E (2006) Antidiabetic effect of garlic (Allium sativum L.) in normal and streptozotocin-induced diabetic rats. Phyto Med 13:624-629

El-Awad ME, Patil K (1990) Haemotemesis due to leech infestation. J Ann Trop Paediatr 10(1):61-62

Estamble BB, Knight R, Chung R (1992) Haematemesis and severe anaemia due to a pharyngeal leech (Myxobdella africana) in a Kenyan child: a case report. Trans R Soc Trop Med Hyg 86 (4): 458

Ghasemi-pirbalouti A (2008) Third listen: plants, traditional medicine and ethnoveterinary, medicinal and aromatic plant, 1 st edn. Saman-Danesh, Shahrekord, pp 158-190

Hadrani A, Debry C, Faucon F, Fingerhut A (2000) Hoarseness due to leech ingestion. J Laryngol Otol 114(2):145-146

Hashmi Fard MA (1996) Evaluating and comparison effects of niclosamid together with garlic and low doses of praziquantel on Hymenolipis nana in the Neka city. PhD thesis of Pharmacy, Tehran J Med Sci

Haycox CL, Odland PB, Clotrea MD, Raugi GJ (1995) Indicatons and complications of medicinal leech therapy. J Am Acad Dermatol 33:1053-1055

Hemmati M, Sat V, Slgee Gh (2002) A case report of vomiting blood with esophageal leech biting. Kermanshah J Med Sci 6(4):55-58

Isaacsohn JL, Moser Stein EA, Dudley DJA, Liskov E et al (1998) Garlic powder and plasma lipids and lipoproteins: a multicenter, randomized, placebo-controlled trial. Arch Intern Med 158:1189-1194

Kazemi A, Bajoghli SH (2002) Two case report alimentary hemorrhagic in children with leech. J Res Med Sci 4(8):95-96

Koscienly J, Klussendorf D, Latza R, Schmitt R, Radtke H, Sieqel G (1999) The antiatherosclerotic effect of Allium sativum. Atherosclerosis 144:237-249

Ledezma E, Apitz-Castro R (2006) Ajoene the main active compound of garlic (Allium sativum): a new antifungal agent. Rev Iberoam Micol 23:75-80

Lun ZR, Burri C, Menzinger M (1994) Antiparasitic effects of diallyl trisulphaide (dasuansu) on human and animals pathogenic protozoa (Trypanosoma sp. E. histolytica \& G. lamblia) in vitro. Ann Soc Belge Méd Trop 74:51-59

Madill J, Hovingh P (2007) Freshwater leech (Annelida: Hirudinida) distribution in the Canadian Province of Newfoundland and Labrador and adjacent regions: check-list, new records, new pigmentation forms, and Pleistocene refugia. Magnolia, Zootaxa, pp 1-21
Mayeux PR, Agrawal KC, Tou JS, King BT, Lippton HL, Hyman AL et al (1988) The pharmacological effects of allicin a constituent of garlic oil. Agents and pharmacological effects of allicin, a constituent of garlic oil. Agents Actions 25:182-190

McGrindle BW, Helden E, Conner WT (1998) Garlic extract therapy in children with hypercholesterlemia. Arc Pediatr Adolesc Med 152:1089-1094

Mirzaei Nl (2005) A case report of epistaxis and haemoptesis at causes leech biting. J Kurdistan Med Sci 11:84-87

Pandey CK, Sharma R, Baronia A, Agarwal A, Singh IV (2000) An unusual case of respiratory distress: live leech in the larynx. Anesth Analog 90(5):1227-1228

Raj SM, Radzi M, Tee Mh (2000) Severe rectal bleeding due to leech bite. Am J Gastroenterol 95(6):1067

Sabayan B, Foroughinia F, Chohedry A (2007) A postulated role of garlic organosulfur compounds in prevention of valproic acid hepatotoxicity. Med Hypotheses 68:512-514

Schenkova J, Sychra J, Kubova B (2005) The freshwater leeches (Clitellata: Hirudinida) of the Czech Republic - list of taxa and remarks on rare and endangered species. Department of Zoology and Botany, Faculty of Science, Masaryk University, Kotlarska, 2 (6): $11-37$

Soffar SA, Mokhtar GM (1991) Evaluation of antiparasitic effects of aqueous garlic extract in hymenolepiasis and giardiasis. Parasitology 21:497-502

Su CC, Chen GW, Tan TW, Lin JG, Chung JG (2006) Crude extract of garlic induced caspase-3 gene expression leading to apoptosis in human colon cancer cells. In Vivo 20:85-90

Sumioka I, Hayama M, Shimokawa Y, Shiraishi S, Tokunaga A (2006) Lipid-lowering effect of monascus garlic fermented extract (MGFE) in hyperlipidemic subjects. Hiroshima J Med Sci 55:59-64

Vera C, Blu A, Torres M (2005) Leeches, today and yesterday present parasites. Rev Chilena Infectol 22:32-37 [in Spanish]

Wallis RB (1988) Hirudins and the role of thrombin: lessons from leeches. Trends Pharmacol Sci 9:425-427

Yaghmaee M (2000) An abnormal vaginal bleeding at causes of leech. Zahedan J Res Med Sci 3(1):41-43

You WC, Blot WJ, Chang YS, Ershow A, Yang ZT, An Q et al (1989) Allium vegetables and reduced risk of stomach cancer. $J$ Natl Cancer Inst 81:162-164

Zargari A (1996) Medicinal plants. Tehran University Press, Tehran, pp $619-620$ 